\title{
Nocturnal enuresis
}

\author{
R. Yavuz Akman \\ Başkent University Medical Faculty, Department of Urology, Başkent University Istanbul Hospital, Istanbul, Turkey
}

\begin{abstract}
Summary
Nocturnal enuresis is one of the most common urinary problems in children and is observed in about 15-20 percent of children aged 5 years. Nocturnal enuresis resolves at a rate of $15 \%$ per year, so $99 \%$ of children are dry by the age of fifteen years. Enuresis can be defined as repetitive bed wetting while sleeping. Enuresis in children without any other lower urinary tract (LUT) symptoms -excluding nocturia- and without a history of bladder dysfunction is defined as monosymptomatic enuresis. Most of the enuretic children belong to this group. A bladder dysfunction must be kept in mind in an enuretic child having day time symptoms. Behavioral treatment, alarm treatment and pharmacological treatment are the most frequently used approaches for treatment. In all treatment modalities and especially in alarm treatment, the motivation and active involvement of the family and the child are very important. (Turk Arch Ped 2012; 47: 80-5)
\end{abstract}

Key words: Nocturnal enuresis, incontinence, enuretic alarm, desmopressin

\section{Introduction}

Nocturnal enuresis (NE) is a very common problem affecting especially primary school children. The origin of the term enuresis comes from the old Greek word " En- + ourein" which means to urinate in. Scientific articles related to nocturnal enuresis stand on Ebers Papyrus (1550 B.C) (1). In this papyrus, treatments including juniper seed and cupressus were recommended for NE. Although NE is a benign disease, it may lead to severe dissapointment for affected children and their families. In addition, it may lead to severe diffidence and compliance problems in the child.

\section{Definitions}

International Child Continence Society (ICCS) determined the terminology related to lower urinary tract (LUT) function in 2006. Intermittent incontinence is escape of urine in certain amounts. It may occur in daytime and/or in the night and this is valid only for children of at least 5 years of age. Enuresis is intermittent incontinence which occurs during sleep (2).

Enuresis in children in whom no other lower urinary tract (LUT) finding is present and who have no history of bladder dysfunction is defined as monosymptomatic NE. Other children with enuresis and children with other LUT symptoms are in the non-monosymptomatic enuresis group. The LTU symptoms compatible with this definition include increased/decreased frequency of urination, daytime incontinence, urgency, hesitancy, straining, poor stream, intermittency, holding maneuvers, incomplete emptying, postvoid dribbling and genital or LUT pain. $80 \%$ of the children with enuresis are monosymptomatic.

If a definition is made by starting time, primary NE defines patients who had never been dry starting from birth and secondary NE defines patients who had stayed dry at least for 6 months and then started to wet again (3).

\section{Epidemiology}

Many studies related to the prevalence of nocturnal enuresis have been performed in our country and abroad (4-9). The prevalence has been found to be $20-25 \%$ in children aged 4 years old. While the prevalence is $10-15 \%$ at the age of 5-7 years, it decreases to approximately $0.5-2.2 \%$ at the age of 15 years and older by showing spontaneous recovery each year with a rate of approximatley $15 \%$ (4-6). In the studies performed in our country, the prevalence has been reported to be $11.5-12.4 \%$ between the ages of 6 and $16(7,8)$. 
While primary NE is observed in boys of young age group with a higher rate, it is observed with an equal rate in male and female patients in adolescence and adulthood (9). The prevalence of nocturnal enuresis is similar in all countries in the world.

\section{Etiology and pathogenesis}

The reasons of nocturnal enuresis have not been fully elucidated. Many different theories including genetic factors, changes in vasopressin release and related nocturnal polyuria, abnormal bladder dynamics, decreased nocturnal bladder capacity and wakening disorders have been suggested in the etiology.

\section{Genetic factors}

Genetic factors play a considerably important role in NE and in some urinary incontinence conditions. The genetics of nocturnal enuresis has been investigated in many structural and molecular genetic studies. While structural genetic approaches are conducted with studies performed in families and twins, molecular genetic studies are performed with chromosomal transfer studies (10).

Family studies have demonstrated the prevalence in the families of the affected individuals. In epidemiologic studies, it was found that enuresis was observed with a rate of $9.6-40 \%$ in the father, with a rate of $20-25 \%$ in the mother and with a rate of $60-70 \%$ in the relatives of a child with NE (11-14). In an epidemiological cross-sectional study performed in 3206 children, it was demonstrated that the risk of NE increased 5-7 fold, if a history of NE was present in the mother or in the father and 11.3 fold, if a history of NE was present in both the mother and the father (15). In a study performed in 338 twins, NE association was found with a rate of $68 \%$ in monozygotic twins and $36 \%$ in dizygotic twins (16). Genetic studies have demonstrated that especially $12 q, 13 q$ and $22 q$ constitute the enuretic gene family (17-19).

\section{Nocturnal polyuria}

The most important factors leading to nocturnal polyuria in children are as follows (20):

- Fluid intake in the night

- High load of solids in the night

- High intake of fluid and solids in daytime

- Release of antidiuretic hormone (ADH) in the night

Excessive nocturnal urine production in many enuretic children constituted the starting point of current enuresis studies. Normally, ADH levels are higher during the night compared to day time and as a result, urine output is $50 \%$ lower in the night (21). Enuretic children have been shown to have no increase in physiological nocturnal ADH release and to produce more urine than they can keep in their bladders as a result (22). Stretching of the bladder may also affect the release of $A D H$ in the night. Studies have shown that $A D H$ release increases as a response to stretching of the bladder and decreases when the bladder is emptied.

\section{Decreased nocturnal bladder capacity}

The effects of bladder dysfunction on NE have been a subject of interest and research. Many studies have shown that bladder capacity is decreased in the night in a great proportion of the patients with enuresis. Although the effects of dysfunction on NE have not been fully elucidated, many studies have been performed on this subject $(23,24)$. Decrease in bladder capacity is related to contraction before filling rather than being related to anatomic factors.

Watanabe et al. $(23,24)$ performed electroencephalogram (EEG) and cystometry during sleep in enuretic children and found detrusor contraction which resulted in enuresis in $32 \%$ of these children.

\section{Difficulty in awakening}

Stretching of the bladder and detrusor contraction are considerably strong awakening signals (25). Therefore, epidemiological studies have shown that enuretic children are "deep sleepers" as many families have also emphasized. However, this does not necessarily mean that the EEGs of these children are different from those of dry children. Hence, there are many EEG studies which presented evidence in favour of this (26). The main problem in these children is in perception of bladder fullness and contractions and inhibition by upper centers without leading to urination. Actually, this is an awakening disorder rather than a sleep disorder.

\section{Diagnostic evaluation}

Children with enuresis are generally assessed by the general practitioner, pediatrician or pediatric urologist in the primary care. The main aim in the primary care evaluation is to define the children who only wet during the night (children with monosymptomatic enuresis), to find the children with enuresis related to the underlying condition and to make the differentiation.

\section{History}

The most important part of diagnostic evaluation is the history. Especially assessment of urination habits should be focused on in the history. Children with monosymptomatic enuresis have no other complaint except for wetting during sleep. Therefore, the points which should be specifically questioned in differentiation of children with non-monosymptomatic enuresis are as follows:

Urgency -difficulty in getting to the toilet in time

Holding maneuvers- standing on tiptoe, squatting, leg crossing, pressing the perineum with the heels etc.,

Intermittent urination, poor stream and applying abdominal pressure to urinate,

Presence, frequency and type of daytime enuresis,

Frequency of daytime urination (the best method for this is urination diary which will be kept by the family at least for two days),

History of urinary infection,

Constipation and encopresis. 
The patient group with daytime urination complaints are the group with non-monosymptomatic enuresis and these patients should be referred to specialized centers without losing time.

The type and frequency of nocturnal wetting are also important (Every night? Rarely?). the frequency of nocturnal wetting has been reported to be a sign of poor prognosis in terms of treatment (5).

Bladder and bowel functions are closely related. Therefore, questioning bowel habits is also important. In a child with constipation, it is difficult to treat enuresis without treating constipation. Certainly, encopresis should also be questioned.

Questioning about the general health status and development is also important. Symptoms of diabetes or parenchymal renal disease may be found as a result of this questioning.

Questioning about fluid intake habits is very important and the ideal method is keeping a urination diary. Determining daily fluid intake is helpful in demonstrating diabetes and parenchymal renal disease as well as demostrating need for care in desmopressin treatment in children who have a habit of drinking too much water.

Presence or absence of severe snoring and/or nocturnal sleep apnea should be questioned. Some children were reported to stay dry after this pathology was eliminated (27).

Possible psychological behavior disorders should also be interrogated.

\section{Physical examination and laboratory}

Generally, no pathological finding is found on physical examination of children with monosymptomatic NE. However, a detailed physical examination should be performed especially in children with low urine flow or severe incontinence in the daytime and in the night. Normal physical examination should be performed and attention should be given specifically to the abdominal region, sacral region and external genital organs.

Care should be given to the following points:

- Hydronephrosis, globe vesicalis or constipation findings on abdominal examination,

- Examination of the sacral region to determine pilosity and discoloration related to spinal dysraphism,

- Examination of the external genitalia.

The only laboratory test which should be done in monosymptomatic NE is complete urinalysis. Leucocyturia on complete urinalysis suggests infection, glucosuria suggests diabetes and proteinuria suggests parencymal renal diseases.

No blood test is required. Urinary system ultrasonography is also unnecessary (28).

\section{Treatment}

If there is no underlying organic disease and no daytime enuresis, treatment should be started, when the child starts to perceive nocturnal wetting as a problem. Although general advises about subjects including nutrition and urination habits can be given to children of all ages who wet their bed in the night, active treatment should not begin before the age of 6 (28).

The most common methods in treatment are as follows:

1-Supportive treatment

2- Alarm treatment

3- Drug treatment

\section{Supportive treatment methods}

The child and the family should be clearly informed about NE. They should be informed that this is a common condition, its treatment is possible and $15 \%$ of the patients recover spontaneously each year. Normal bladder function and the pathogenesis of enuresis should be explained to the patient in the simplest way.

The child and the family should be advised to keep a calendar on which wet and dry nights are marked. The calendar shows the status of enuresis at baseline and constitutes a basis for measuring response to treatment. In addition, it has an independent treatment effect (29).

A daily urination calender should be arranged for the child. The child should absolutely urinate when he/she wakes up, two times during the school time, one time after school, one time at diner time and one time before going to bed.

Immobility for a long time should be avoided and physical activities should be arranged. Fluid intake in the morning and noon should be free. However, fluid intake should be limited as much as possible during the two hours before going to bed. After dinner and before going to bed salty foods and foods containing calcium which can increase the solute load should be avoided.

If constipation is present, this should be eliminated. Bowel habits should be tried to be adjusted (preferably after breakfast).

\section{Alarm treatment}

An alarm mechanism which activates with urination is used. There are many different types of enuretic alarm devices. The most commonly used type is the one which is put on the arm like a watch with the electrodes stuck to the underwear. Alarm treatment is the best treatment method in children with awakening disorder. Alarm treatment provides dryness in $2 / 3$ of the children (66.6\%) and when the treatment is completed, half of them continue to stay dry (30). The aim of the alarm is to increase the sensitivity against bladder fullness with a conditioned reflex (31) and/or increase bladder storage function in the night (32). Alarm treatment should be recommended to all children with NE.

For a successful alarm treatment the help of the parents is very important. Therefore, it is important that the parents' motivation is high in this treatment method. Every time the alarm rings, the child should be made to get out of the bed and urinate and the alarm should be attached again. Continuity is very improtant in this treatment and the alarm should absolutely be used every night. 
Treatment should be continued at least for 2-3 months. If no success is obtained at the end of this period, the treatment is stopped. If positive developments are observed, the treatment should be continued until the child is dry for 14 consecutive days (28). Although recurrences can occur after a successful treatment, response to a new alarm treatment is high. After dryness is provided, the fluid intake before going to bed is increased gradually and thus, the risk of recurrence is decreased by increasing the capacity of the bladder. If the child stays dry for one month further after this application, the treatment is discontinued.

\section{3-Drug treatment}

The most commonly used drugs include desmopressin acetate which is a synthetic analogue of arginine vasopressin, imipramine hydrochloride which is a tricyclic antidepressant and anticholinergics.

\section{Desmopressin}

Arginine is the synthetic equivalent of vasopressin. It increases the absorption of water in renal distal tubules and increases urine density by decreasing urine output. It is one of the evidence-based treatment methods (33). Approximately $30 \%$ of the children give complete response and $40 \%$ give partial response. While previously nasal sprays had been used, currently tablets which rapidly dissolve in the mouth are being used (34).

Desmopressin is mostly effective in children with nocturnal polyuria (nocturnal urine production higher than $130 \%$ of bladder capacity for age) and normal bladder storage function (35). Children who do not respond to alarm treatment or who can not adapt to alarm treatment can benefit from desmopressin treatment.

Desmopressin is a safe drug which has considerable few side effects even if used for long years. However, there is a point which should be absolutely kept in mind. If excessive water is consumed after the drug is taken, water intoxication which proceeds with hyponatremia and convulsions can occur. Because this side effect was observed with a very high rate with nasal spray form, the indication of use of nasal spray in enuresis has been removed in many countries including our country. The families should be warned about not to drink more than $200 \mathrm{ml}$ water in the night and not to drink water until morning. Tablets which dissolve in the mouth should be taken 30-60 minutes before sleeping. The recommended dose is 120-240 micrograms (the highest dose is 360 micrograms) independent of the age and body weight. Its clinical application is easy and it acts rapidly. The dose is decreased after three months of treatment and its efficiency is tested by discontinuing the drug for an interval of $1-3$ weeks. If recurrence occurs, the efficient dose is started again. Recurrence risk is considerably high after the drug is discontinued (60-70\%) (36). In refractory cases, it can be considered to be used in combination with alarm treatment.

\section{Tricyclic antidepressants}

They have been used for treatment of enuresis since 1960s and shown to be more efficient compared to placebo in many randomized studies $(37,38)$. The most commonly used one is imipramine, but other drugs including amitriptyline and desipramine are also efficient. Their efficiency has been reported to range between $40 \%$ and $70 \%(38,39)$. Tricyclic antidepressants shorten REM phase of sleep, stimulate release of vasopressin and lead to relaxation of detrusor muscle.

The theraputic dose of imipramine is $0.9-1.5 \mathrm{mg} / \mathrm{kg}$ before going to bed. In practice, $25 \mathrm{mg}$ is given before going to bed in children 5-8 years of age and $50 \mathrm{mg}$ is given in older children. $75 \mathrm{mg}$ can be used in children aged 12 years or older. The drug should be discontinued, if cure can not be obtained after use of the appropriate dose for three weeks. Recurrence rate after treatment is considerably high similar to desmopressin. The reccurence rate was found to be $75 \%$ in one study (40).

Although tricyclic antidepressants have neurological side effects including personality change, insomnia, nervoussness, the most important side effect is cardiotoxicity and this can be fatal at high doses (41). Tricyclic antidepressants which had been previously used widely have a limited use in treatment of enuresis at the present time because of all these side effects and limited efficiency.

\section{Anticholinergics}

Anticholinergic drugs which have been proved to be efficient and safe in children include oxybutirine, tolterodine and propiverine (28). None of them is the first-line treatment for enuresis. Oxybutirine is the most commonly used anticholinergic. It inhibits detrusor contractions which can not be supressed. Some studies have shown that they are effective in children who are resistant to other treatments (42).

Anticholinergics can be helpful in children who have daytime complaints resistant to desmopressin and who wet their bed more than two times in the night (43).

Recommended doses are as follows (before going to bed at night): $2 \mathrm{mg}$ tolterodine or $5 \mathrm{mg}$ oxybutirine or $0,4 \mathrm{mg} / \mathrm{kg}$ propiverine.

Anticholinergic drugs are generally well tolerated. The most common side effects include dry mouth, dizziness, facial flushing and constipation. Mood changes can be observed. One of the most frightening side effects is residual urine after urination, because it can lead to urinary infections. 


\section{Table 1. Approach to the child with nocturnal enuresis (43)}

Child with enuresis $>5$ years

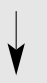

Related problems

- Urological symptoms

- Urinary infection

- Constipation, encopresis

- Abnormal fluid consumption

- Known behaviour disorders

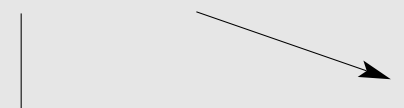

NO

YES

these problems should

be treated primarily

\section{Monosymptomatic NE}

The patient and the family should be interviewed

Detailed information is given

Possible causes are explained

Treatment options are explained

Motivation of the patient and the parents is provided

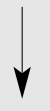

YES

Fluid consumption, urination education and nutritional advises

Completing urination diary

Treatment is recommended individually by interviewing with the parents and the patient

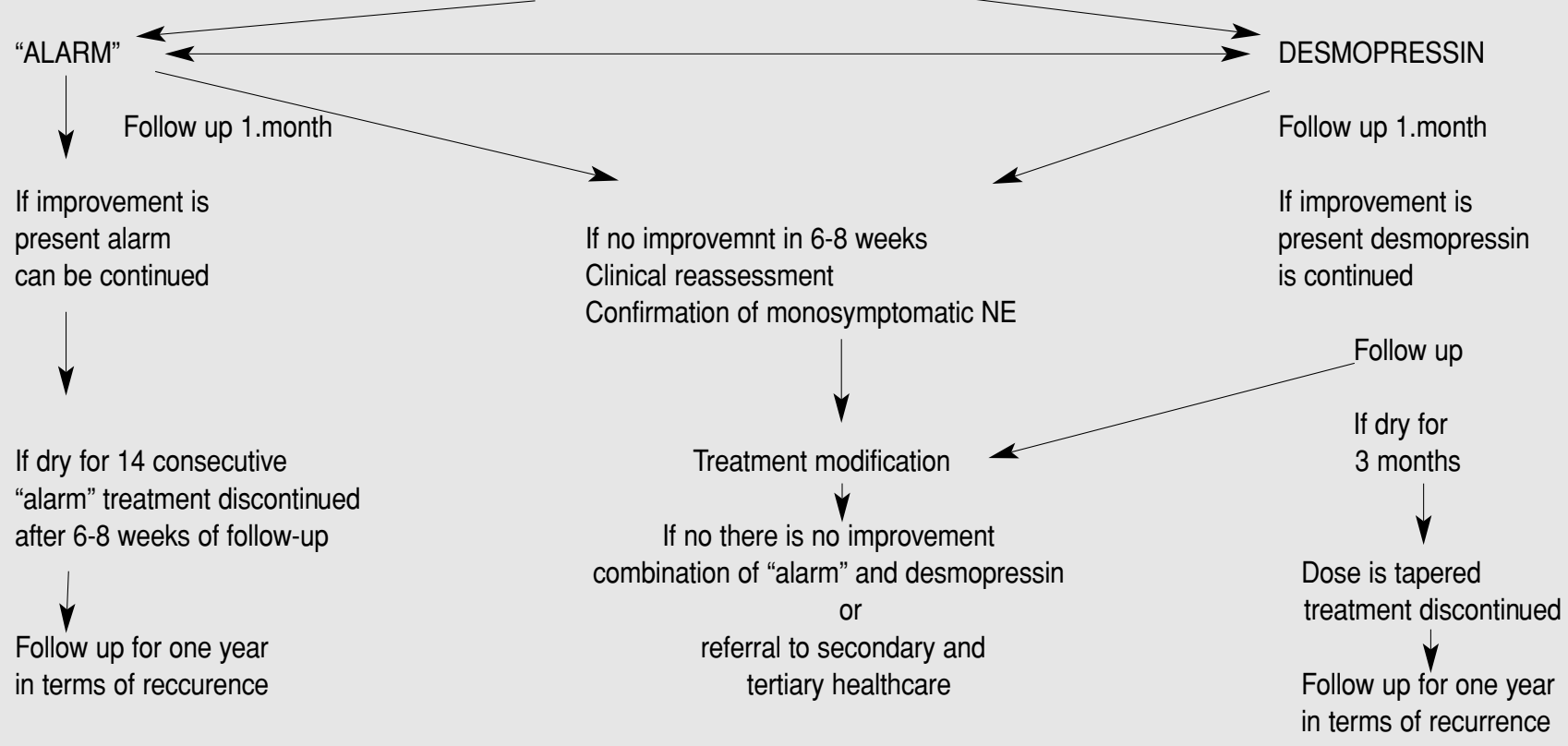




\section{References}

1. Gill D. Enuresis through the ages. Pediatr Nephrol 1995;9:120-2.

2. Neveus T, von Gontard A, Hoebeke P, et al. The standardization of terminology of lower urinary tract function in children and adolescents: report from the Standardisation Committee of the International Children's Continence Society. J Urol 2006;176:314-24.

3. Rassouli R, Holschneider AM, Bolkenius M, et al. Long-term results of Rehbein's procedure: a retrospective study in German-speaking countries. Eur J Pediatr Surg 2003;13:187-94.

4. Yeung CK. Nocturnal enuresis (bedwetting). Curr Opin Urol 2003;13:337-43.

5. Yeung CK, Sreedhar B, Sihoe JD, Sit FK, Lau T. Differences in characteristics of nocturnal enuresis between children and adolescents: a critical appraisal from a large epidemiological study. BJU Int 2006;97:1069-73.

6. Forsythe WI, Redmond A. Enuresis and spontaneous cure rate. Study of 1129 enuretis. Arch Dis Child 1974;49:259-63.

7. Serel TA, Akhan G, Koyuncuoglu HR, et al. Epidemiology of enuresis in Turkish children. Scand J Urol Nephrol 1997;31:537-9.

8. Gur E, Turhan P, Can G, et al. Enuresis: prevalence, risk factors and urinary pathology among school children in Istanbul, Turkey. Pediatr Int 2004;46:58-63.

9. Moore KH, Richmond DH, Parys BT. Sex distribution of adult idiopathic detrusor instability in relation to childhood bedwetting. $\mathrm{Br} \mathrm{J}$ Urol 1991;68:479-82.

10. von Gontard A, Schaumburg H, Hollmann E, Eiberg H, Ritting S. The genetics of enuresis: a review. J Urol 2001;166:2438-43.

11. Bakwin H. Enuresis in children. J Pediatr 1961;58:806-19.

12. Elian M, Elian E, Kaushansky A. Nocturnal enuresis: a familial condition. J R Soc Med 1984;77:529-30.

13. von Gontard A, Hollmann E, Eiberg H, Benden B, Rittig S, Lehmkuhl G. Clinical enuresis phenotypes in familial nocturnal enuresis. Scand $J$ Urol Nephrol Suppl 1997;183:11-6.

14. von Gontard A, Heron J, Joinson C. Family history of nocturnal enuresis and urinary incontinence: results from a large epidemiological study. J Urol 2011;185:2303-7.

15. Jarvelin MR, Vikevainen-Tervonen L, Moilanen I, Huttunen ND. Enuresis in seven-year-old children. Acta Paediatr Scand 1988;77:148-53.

16. Bakwin H. Enuresis in twins. Am J Dis Child 1971;121:222-5.

17. Arnell $H$, Hjalmas $K$, Jagervall $M$, et al. The genetics of primary nocturnal enuresis: inheritance and suggestion of a second major gene on chromosome 12q. J Med Genet 1997;34:360-5.

18. Eiberg $\mathrm{H}$. Total genome scan analysis in a single extended family for primary nocturnal enuresis: evidence for a new locus (ENUR3) for primary nocturnal enuresis on chromosome 22q11. Eur Urol 1998; 33 Suppl 3:34-6.

19. Eiberg H, Berendt I, Mohr J. Assignment of dominant inherited nocturnal enuresis (ENUR1) to chromosome 13q. Nat Genet 1995;10:354-6.

20. Robson WL. Current management of nocturnal enuresis. Curr Opin Urol 2008;18:425-30.

21. George CP, Messerli FH, Genest J, Nowaczynski W, Boucher R, Kuchel Orofo-Oftega M. Diurnal variation of plasma vasopressin in man. J Clin Endocrinol Metab 1975;41:332-8.

22. Rittig S, Knudsen UB, Norgaard JP, Pedersen EB, Djurhuus JC. Abnormal diurnal rhythm of plasma vasopressin and urinary output in patients with enuresis. Am J Physiol 1989;256:F664-71.
23. Watanabe $\mathrm{H}$, Kawauchi $\mathrm{A}$. Is small bladder capacity a cause of enuresis? Scand J Urol Nephrol Suppl 1995;173:37-41.

24. Watanabe H. Nocturnal enuresis. Eur Urol 1998;33 Suppl 3:2-11.

25. Neveus T. Nocturnal enuresis-theoretic background and practical guidelines. Pediatr Nephrol 2011;26:1207-14.

26. Bader G, Neveus T, Kruse S, Sillen U. Sleep of primary enuretic children and controls. Sleep 2002;25:579-83.

27. Cinar U, Vural C, Cakir B, Topuz E, Karaman MI, Turgut S. Nocturnal enuresis and upper airway obstruction. Int $\mathrm{J}$ Pediatr Otorhinolaryngol 2001;59:115-8.

28. Neveus T, Eggert P, Evans J, et al. Evaluation of and treatment for monosymptomatic enuresis: a standardization document from the International Children's Continence Society. J Urol 2010;183:441-7.

29. Glazener CM, Evans JH. Simple behavioural and physical interventions for nocturnal enuresis in children. Cochrane Database Syst Rev 2004:CD003637.

30. Glazener CM, Evans JH, Peto RE. Alarm interventions for nocturnal enuresis in children. Cochrane Database Syst Rev 2005:CD002911.

31. Butler RJ, Holland P, Gasson S, Norfolk S, Houghton L, Penney M. Exploring potential mechanisms in alarm treatment for primary nocturnal enuresis. Scand J Urol Nephrol 2007;41:407-13.

32. Oredsson AF, Jorgensen TM. Changes in nocturnal bladder capacity during treatment with the bell and pad for monosymptomatic nocturnal enuresis. J Urol 1998;160:166-9.

33. Glazener CM, Evans JH. Desmopressin for nocturnal enuresis in children. Cochrane Database Syst Rev 2002:CD002112.

34. Meltzer LJ, Johnson C, Crosette J, Ramos M, Mindell JA. Prevalence of diagnosed sleep disorders in pediatric primary care practices. Pediatrics 2010;125:e1410-8.

35. Hunsballe JM, Hansen TK, Rittig S, Pedersen EB, Djurhuus JC. The efficacy of DDAVP is related to the circadian rhythm of urine output in patients with persisting nocturnal enuresis. Clin Endocrinol (Oxf) 1998:49:793-801.

36. Wille S. Comparison of desmopressin and enuresis alarm for nocturnal enuresis. Arch Dis Child 1986;61:30-3.

37. Maclean RE. Imipramine hydrochloride (Tofranil) and enuresis. Am J Psychiatry 1960;117:551.

38. Glazener CM, Evans JH, Peto RE. Tricyclic and related drugs for nocturnal enuresis in children. Cochrane Database Syst Rev 2003:CD002117.

39. Smellie JM, McGrigor VS, Meadow SR, Rose SJ, Douglas MF Nocturnal enuresis: a placebo controlled trial of two antidepressant drugs. Arch Dis Child 1996;75:62-6.

40. Fritz GK, Rockney RM, Yeung AS. Plasma levels and efficacy of imipramine treatment for enuresis. J Am Acad Child Adolesc Psychiatry 1994;33:60-4.

41. Swanson JR, Jones GR, Krasselt W, Denmark LN, Ratti F. Death of two subjects due to imipramine and desipramine metabolite accumulation during chronic therapy: a review of the literature and possible mechanisms. J Forensic Sci 1997;42:335-9.

42. Kosar A, Arikan N, Dincel C. Effectiveness of oxybutynin hydrochloride in the treatment of enuresis nocturna--a clinical and urodynamic study. Scand J Urol Nephrol 1999;33:115-8.

43. Avanoğlu A, Baskın E, Söylemezoğlu O, Tekgül S, Zilan O, Zorludemir Ü. Türkiye Enürezis Çalışma Grubu. İçinde: Türkiye Enürezis Tedavi Kılavuzu 2010;1-16. 